\title{
Should annuloplasty prosthesis be selected dependent on the location of prolapse in mitral valve repair for type II dysfunction?
}

\author{
Naonori Kawamoto, MD, ${ }^{\text {a }}$ Tomoyuki Fujita, MD, PhD, ${ }^{a}$ Satsuki Fukushima, MD, PhD, ${ }^{\mathrm{a}}$ \\ Hiroki Hata, MD, PhD, ${ }^{a}$ Yusuke Shimahara, $\mathrm{MD},{ }^{a}$ Koko Asakura, $\mathrm{PhD},{ }^{\mathrm{b}}$ and Junjiro Kobayashi, MD, $\mathrm{PhD}{ }^{\mathrm{a}}$
}

\section{ABSTRACT}

Objective: This study explored the influence of prosthesis selection on long-term outcomes in patients who underwent mitral valve repair for mitral insufficiency (MI) due to type II dysfunction.

Methods: We retrospectively reviewed 452 patients with MI who underwent mitral valve repair for type II dysfunction between 2001 and 2014. Of these, 167 patients $(37 \%)$ presented with anterior leaflet prolapse (anterior group) and $285(63 \%)$ presented with posterior prolapse (posterior group). Full rings were applied in 95 patients $(57 \%)$ in the anterior group and in 54 patients $(19 \%)$ in the posterior group, and partial bands were applied in all others. We compared long-term outcome and change of MI severity over time between patients with partial-band and full-ring repair in the anterior and in the posterior groups using a mixed-effect model with repeated measures and propensity score-matched analysis.

Results: Ten-year survival of the cohort was $90.5 \%$. Echocardiography revealed $\mathrm{MI} \geq 3$ at follow-up in 58 patients $(12.8 \%)$. Twenty-one patients $(4.6 \%)$ required reoperation; freedom from reoperation was $92.1 \%$ at 10 years. The MI severity over time in patients in the anterior group was higher than that in patients in the posterior group $(P<.0001)$. Moreover, MI severity over time in patients with the partial band was higher than patients with the full ring in the anterior group $(P=.0176)$. Propensity score-matched analysis in the anterior group, but not in the posterior group, revealed a significantly higher MI severity in patients with the partial band than those with the full ring over the study period $(P=.04)$.

Conclusions: Full-ring annuloplasty is indicated in the setting of anterior prolapse to prevent recurrent MI, whereas prosthesis type is not a determinant of recurrent $\mathrm{MI}$ in the setting of posterior prolapse. ( $\mathrm{J}$ Thorac Cardiovasc Surg 2017;154:1915-24)

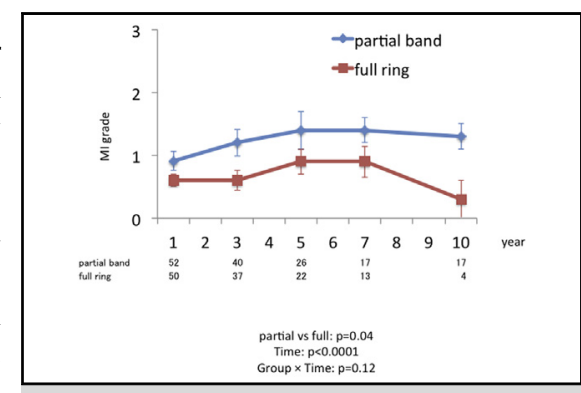

After propensity score matching between patients with partial-band and full-ring repair in the anterior lesion group, using a mixed-effect model, mitral insufficiency (MI) severity over time in patients with partial-band repair was significantly higher than in patients with full-ring repair

\section{Central Message}

In mitral valve anterior lesions, full-ring annuloplasty reduced severity of mitral insufficiency over time and improved long-term outcomes compared with partial-band annuloplasty.

\section{Perspective}

The long-term durability of mitral valve repair of anterior lesions is inferior to that of posterior lesions. The present study demonstrates the importance of prosthesis selection in improving the long-term outcomes of mitral valve repair

See Editorial Commentary page 1925 . of anterior lesions.
From the Departments of ${ }^{\mathrm{a}}$ Cardiac Surgery and ${ }^{\mathrm{b}}$ Data Science, National Cerebral and Cardiovascular Center, Osaka, Japan.

Read at the 96th Annual Meeting of The American Association for Thoracic Surgery, Baltimore, Maryland, May 14-18, 2016.

Received for publication May 13, 2016; revisions received June 9, 2017; accepted for publication June 26, 2017; available ahead of print July 26, 2017.

Address for reprints: Tomoyuki Fujita, MD, PhD, Department of Cardiac Surgery, National Cerebral and Cardiovascular Center, 5-7-1 Fujishirodai, Suita, Osaka 565-8565, Japan (E-mail: tomofujita@nifty.com). $0022-5223 / \$ 36.00$

Copyright (C) 2017 Published by Elsevier Inc. on behalf of The American Association for Thoracic Surgery

http://dx.doi.org/10.1016/j.jtcvs.2017.06.049 


$$
\begin{aligned}
& \text { Abbreviations and Acronyms } \\
& \begin{aligned}
\text { LA } & =\text { left atrial } \\
\text { MI } & =\text { mitral insufficiency } \\
\text { NYHA } & =\text { New York Heart Association } \\
\text { TR } & =\text { Tricuspid regurgitation }
\end{aligned}
\end{aligned}
$$

excellent long-term outcome. ${ }^{1-4}$ The repair procedure for posterior leaflet prolapse has been standardized as quadrangular or triangular resection and suture. ${ }^{5}$ In contrast, anterior leaflet or bileaflet prolapse needs more complex repair procedures, such as implantation of artificial chordae. ${ }^{6}$ As a result, the long-term durability of mitral repair for anterior lesions is reportedly not as good as that for posterior lesions. ${ }^{6-9}$

An annuloplasty ring is an essential part of mitral valve repair procedures to remodel the annulus and consequently stabilize the repair for long-term durability. We previously reported ${ }^{10}$ that a small-sized prosthesis for mitral valve repair may result in prosthesis-patient mismatch and thus, a largesized prosthesis should be placed. However, the influence of the type of annuloplasty prosthesis on long-term durability has not been fully established. ${ }^{11}$ Although the shape of a native mitral annulus changes during the cardiac cycle, the saddle shape that is formed during the systolic phase has recently been preferred as the prosthesis shape. ${ }^{12}$ In contrast, a flexible partial band is reportedly ideal to decrease anterior mitral leaflet strain and maintain aortic curtain motion, ${ }^{13}$ although it has been reported that the annular geometry is flattened in cases of advanced MI. ${ }^{14}$ The purpose of this study was to review long-term outcomes and valve function after mitral valve repair in patients with type II dysfunction, and to compare the influence of type of annuloplasty prosthesis dependent on the location of the leaflet prolapse.

\section{MATERIALS AND METHODS \\ Patients}

This study included a consecutive series of 452 patients (297 men and 155 women; mean age, $60.3 \pm 12.7$ years; range, $19-84$ years) who underwent mitral valve repair for type II severe MI using a prosthetic full ring or partial band in our institution between 2001 and 2014. The data were collected from medical charts, supplemented by telephone interviews for patients who were treated by a distant physician. Patients undergoing concomitant aortic valve surgery were excluded. Preoperatively, 32 patients $(7.1 \%$ ) were New York Heart Association (NYHA) functional class III or IV. The area of prolapse was the anterior leaflet only in 95 patients $(21 \%)$, the posterior leaflet only in 285 patients $(63 \%)$, the anterior and posterior leaflets (bileaflet) in 72 patients (16\%), and a commissure only in 6 patients $(1.3 \%)$. Postoperatively, patients regularly visited the outpatient clinic of the National Cerebral and Cardiovascular Center for medical follow-up. The follow-up rates for survival and reoperation were $99 \%$ and the mean follow-up period was $5.9 \pm 3.9$ years. The follow-up rate for MI $\geq 3$ was $73.6 \%$. Our institutional review board approved the study and waived the need for patient consent for this retrospective study.

Patients were divided into the following 2 groups according to the location of the prolapsing leaflet: anterior leaflet, including bileaflet prolapse (anterior group, $\mathrm{n}=167$ ); and isolated posterior leaflet (posterior group, $n=265$ ). Patients with isolated prolapse of a commissure were classified as having bileaflet prolapse. Preoperative patient characteristics and hemodynamic characteristics are shown in Table 1.

\section{Surgical Procedures}

Operative data are shown in Table 1. All patients underwent mitral annuloplasty using a prosthetic full ring or partial band. Repair technique (eg, resection and suture, chordal replacement, or edge-to-edge repair) depended on the leaflet involvement. The annuloplasty prosthesis size was selected in correspondence with the intertrigone distance measured with the sizer provided, without downsizing. When the intertrigone distance was obscure, the length of the anterior leaflet was used for prosthesis size selection (Videos 1 and 2).

Concomitant cardiac procedures included coronary artery bypass grafting in 38 patients $(8.4 \%)$, tricuspid annuloplasty in 74 patients $(16 \%)$, maze procedure in 133 patients $(29 \%)$, and other procedures in 25 patients $(5.5 \%)$.

\section{Echocardiography}

Echocardiography was performed within 30 days before surgery; within 10 days postoperatively; and 1, 3, 5, 7, 10, and 15 years postoperatively whenever possible. Doppler echocardiography was used to define MI as grade 0 (no MI), 1 (trivial), 2 (mild), 3 (moderate), or 4 (severe). Severe was defined as either central jet MI of more than $40 \%$ of the left atrial (LA) area, holosystolic eccentric jet MI, vena contracta $>0.7 \mathrm{~cm}$, regurgitant volume $>60 \mathrm{~mL}$, regurgitant fraction $>50 \%$, or effective regurgitant orifice $>0.40 \mathrm{~cm}^{2}$. MI was classified as trivial, mild, or moderate by an expert engineer and expert doctor individually.

Each patient's cardiac function was assessed for residual MI, tricuspid regurgitation (TR), fractional shortening, left ventricular end-diastolic diameter and end-systolic diameter, mean transmitral pressure gradient, LA diameter, and peak tricuspid regurgitant pressure gradient. M-mode echocardiography was used to measure LA diameter on images created via the parasternal short-axis view at the level of the aortic valve at ventricular end systole. Tricuspid regurgitant pressure gradient was defined as the value of the right ventricular systolic pressure (systolic pulmonary artery pressure) minus the central venous pressure. ${ }^{15}$ Recurrent MI was defined as moderate or severe MI after the initial repair (MI $\geq 3$ at follow-up). The number of patients examined by echocardiography was $373(82.5 \%)$ at 1 year, $197(60 \%)$ at 3 years, $213(81.9 \%)$ at 5 years, and 118 $(58.1 \%)$ at 10 years after surgery (Table E1). Although some patients who were treated by distant physicians were not examined by institutional echocardiography, clinical progress was regularly reported to our institute. The background, the characteristics, and the procedural details were not significantly different between the patients examined by institutional echocardiography and the patients not examined (see Table E2).

\section{Statistical Analysis}

Categorical data in Table 1 and Table 2 are shown as number (\%), and continuous data were checked for normality distributions using Shapiro-Wilk test (Table E3). If the distributions were normal, the continuous data are shown as mean \pm standard deviation. If not, median and interquartile ranges are used. Patient characteristics are shown in Table 1, 1-year echocardiographic findings are in Table 2, and MI $\geq 3$ at followup and the regurgitant jet site in full-ring versus partial-band repair are shown in Table 3 and were compared by univariate analyses using the $\chi^{2}$ test (for categoric variables) and the Mann-Whitney $U$ test (for continuous variables). To handle missing data, pairwise deletion was used. Echocardiographic measures of MI severity were analyzed over the study period. Mixed-effect model with repeated measures was fit to evaluate the association between MI severity and each group of the patients (anterior or posterior prolapse, full ring or partial band, or flexible ring or 
TABLE 1. Patient characteristics, preoperative echocardiographic findings, and surgical procedure in both groups

\begin{tabular}{|c|c|c|c|c|}
\hline & All & Anterior (\%) & Posterior (\%) & $P$ value \\
\hline No. of patients & 452 & 167 & 285 & \\
\hline Age (y) & $61(53-70)$ & $62(53-70)$ & $61(54-70)$ & .95 \\
\hline Male sex & 297 (66) & $108(64)$ & $189(66)$ & .72 \\
\hline $\operatorname{BSA}\left(\mathrm{m}^{2}\right)$ & $1.63 \pm 0.19$ & $1.62 \pm 0.17$ & $1.63 \pm 0.19$ & .33 \\
\hline NYHA functional class III or IV & $35(7.7)$ & $10(6)$ & $25(8.7)$ & .28 \\
\hline Beta blocker & $69(15.2)$ & $28(16.7)$ & $41(14.4)$ & .51 \\
\hline $\mathrm{CCB}$ & $85(18.8)$ & $28(16.7)$ & $57(20)$ & .37 \\
\hline HT & $186(41.1)$ & $62(37.1)$ & $124(43.5)$ & .2 \\
\hline HL & $108(23.8)$ & $39(23.3)$ & $69(24.2)$ & .88 \\
\hline DM & $45(9.9)$ & $12(7.2)$ & $33(11.6)$ & .14 \\
\hline $\mathrm{FEV}_{1}<70 \%$ & $51(11.2)$ & $23(13.7)$ & $28(9.8)$ & .18 \\
\hline CRF on HD & $2(0.4)$ & $2(1.2)$ & $0(0)$ & .06 \\
\hline Af & $163(35)$ & $73(43)$ & $90(31)$ & .01 \\
\hline Thyroid disorder & $22(4.8)$ & $9(5.4)$ & $13(4.6)$ & .67 \\
\hline \multicolumn{5}{|c|}{ Preoperative echocardiographic findings } \\
\hline MI grade 4 & $287(64)$ & $95(57)$ & $192(67)$ & .1 \\
\hline $\operatorname{LVDd}(\mathrm{mm})$ & $58.4 \pm 6.3$ & $58.3 \pm 6.4$ & $58.4 \pm 6.3$ & .86 \\
\hline LVDs (mm) & $35.8 \pm 5.7$ & $35.8 \pm 5.8$ & $35.9 \pm 5.7$ & .87 \\
\hline $\mathrm{LAD}(\mathrm{mm})$ & $49(45-55)$ & $50(45-57)$ & $49(44-54)$ & .17 \\
\hline TRPG $(\mathrm{mm} \mathrm{Hg})$ & $29(23-37.75)$ & $28(23-35)$ & $30(22-38.5)$ & .32 \\
\hline$\% \mathrm{FS}$ & $38(34-43)$ & $38.5(34-44)$ & $38(34-42)$ & .73 \\
\hline TR grade 3 or 4 & $21(4.6)$ & $10(5.9)$ & $11(3.8)$ & .03 \\
\hline \multicolumn{5}{|l|}{ Repair technique } \\
\hline Partial band & $303(67)$ & $72(43)$ & $231(81)$ & $<.0001$ \\
\hline Full ring & $149(33)$ & $95(57)$ & $54(19)$ & $<.0001$ \\
\hline Flexible ring & $312(69)$ & $80(48)$ & $232(81)$ & $<.0001$ \\
\hline Rigid/semirigid ring & $140(31)$ & $87(52)$ & $53(19)$ & $<.0001$ \\
\hline Resection and suture & $341(75)$ & $67(40)$ & $274(96)$ & $<.0001$ \\
\hline Chordal replacement & $141(31)$ & $131(78)$ & $10(3.5)$ & $<.0001$ \\
\hline Edge-to-edge repair & $73(16)$ & $48(28)$ & $25(8.7)$ & $<.0001$ \\
\hline \multicolumn{5}{|l|}{ Concomitant procedure } \\
\hline Maze procedure & $133(29)$ & $61(36)$ & $72(25)$ & .01 \\
\hline TAP & $74(16)$ & $36(21)$ & $38(13)$ & .02 \\
\hline CABG & $38(8.4)$ & $17(10)$ & $21(7.3)$ & .3 \\
\hline Other & $25(5.5)$ & $8(4.7)$ & $17(5.9)$ & .3 \\
\hline
\end{tabular}

Values are presented as $\mathrm{n}$, median (range), $\mathrm{n}(\%)$, or mean \pm standard deviation. The anterior group was those patients with anterior leaflet prolapse, including commissure leaflet prolapse, and the posterior group had only posterior leaflet prolapse. BSA, Body surface area; NYHA, New York Heart Association; CCB, calcium channel blocker; $H T$, hypertension; $H L$, hyperlipidemia; $D M$, diabetes mellitus; $F E V_{l}$, forced expiratory volume in 1 second; $C R F$ on $H D$, chronic renal failure on hemodialysis; $A f$, atrial fibrillation; $M I$, mitral insufficiency; $L V D d$, left ventricular end-diastolic diameter; $L V D s$, left ventricular end-systolic diameter; $L A D$, left atrial diameter; $T R P G$, tricuspid regurgitant pressure gradient; $\% F S$, fractional shortening; $T R$, tricuspid regurgitation; $T A P$, tricuspid annuloplasty; $C A B G$, coronary artery bypass grafting.

rigid/semirigid ring). Fixed effects were group of patients, time after operation, and group of patients by time after operation interaction, whereas the random effect was patients. Missing data in the mixed-effect models for repeated measures were handled by using direct likelihood method. The Cox hazard model was used to predict risk factors for $\mathrm{MI} \geq 3$ at follow-up and for reoperation. Independent risk factors for $\mathrm{MI} \geq 3$ at follow-up and reoperation were identified by multivariate Cox proportional hazards analysis. Variables with a univariate $P$ value $<.2$ were entered into the multivariate model. Survival, freedom from reoperation, and combined end point curves were obtained using the Kaplan-Meier method and were compared between groups using the log-rank test. All statistical analyses were performed using SPSS version 22 (IBM-SPSS Inc, Armonk, NY).

\section{Propensity-Matched Analysis}

Because baseline characteristics were different between the patients with partial-band and full-ring repair in the anterior group (Table 4), propensitymatched analysis was used to compare MI severity over time between patients with partial-band and full-ring repair in the anterior group. A propensity score was calculated with multiple logistic regression using the following 18 variables: age, sex, body surface area, NYHA functional class III or IV, preoperative beta blocker use, preoperative calcium channel blocker use, hypertension, hyperlipidemia, diabetes mellitus, forced expiratory volume in 1 second $>70 \%$, chronic renal failure on hemodialysis, preoperative atrial fibrillation, TR grade $>2$, coronary artery disease, left ventricular enddiastolic diameter, LA diameter, \% fractional shortening, and thyroid 


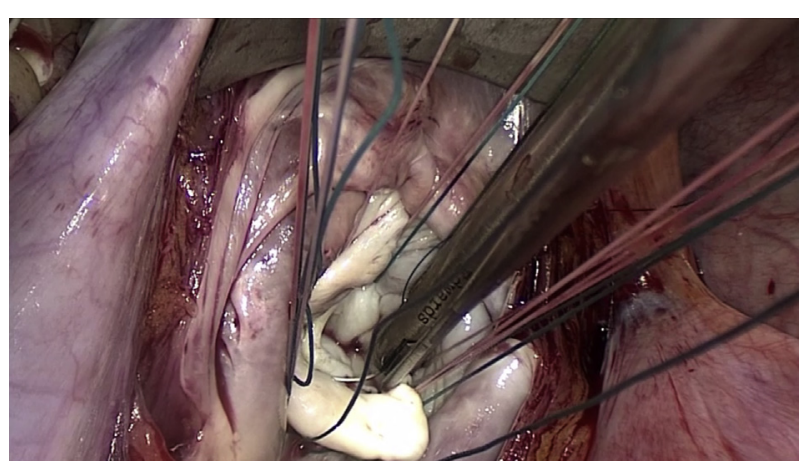

VIDEO 1. Resection and suture technique and partial-band annuloplasty for posterior leaflet prolapse. The same technique was used both for open mitral valve repair and for minimally invasive mitral valve repair via small right thoracotomy. Video available at: http://www.jtcvsonline.org/ article/S0022-5223(17)31368-5/addons.

disorder. Baseline characteristics in the unmatched patients and the matched patients undergoing partial-band and full-ring procedure in the anterior group are shown in Table 4. Standardized differences were used to evaluate the balance between the baseline variables. $C$ statistic $(=0.74)$ was calculated to evaluate the goodness-of-fit of this model.

\section{RESULTS}

\section{Surgical Procedures and In-Hospital Outcome}

Valve repair technique was resection and suturing in 341 patients $(75 \%)$, chordal replacement in 141 patients $(31 \%)$, and edge-to-edge repair in 73 patients $(16 \%)$. Of the 3 repair techniques, resection and suturing was used most frequently in the posterior group (254 patients [96\%]) and chordal replacement was used most frequently in the anterior group (131 patients [78\%]). Regarding the choice of prosthetic type, the full ring was used most frequently $(\mathrm{n}=95[57 \%])$ in the anterior group, and the type of full ring was most frequently rigid or semirigid $(52 \%)$. In contrast, the partial band and the flexible ring were chosen

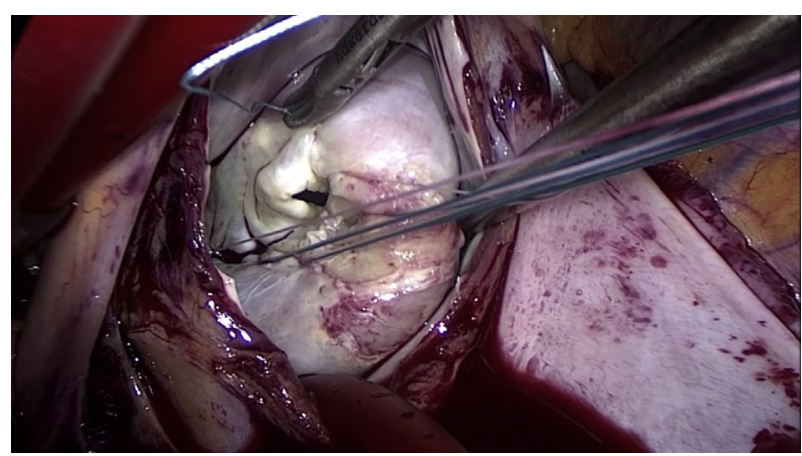

VIDEO 2. Chordal replacement with polytetrafluoroethylene suture and full-ring annuloplasty for anterior leaflet prolapse. The same technique was used both for open mitral valve repair and for minimally invasive mitral valve repair via small right thoracotomy. Video available at: http:// www.jtcvsonline.org/article/S0022-5223(17)31368-5/addons.
TABLE 2. One-year follow-up echocardiographic findings after mitral valve repair

\begin{tabular}{lcccc}
\hline & All $(\mathbf{n}=\mathbf{3 7 3})$ & $\begin{array}{c}\text { Anterior } \\
(\mathbf{n}=\mathbf{1 5 6})\end{array}$ & $\begin{array}{c}\text { Posterior } \\
(\mathbf{n}=\mathbf{2 1 7})\end{array}$ & $\boldsymbol{P}$ value \\
\hline MI grade $\geq 2$ & $49(13.1)$ & $28(17.9)$ & $21(10.3)$ & .02 \\
LVDd $(\mathrm{mm})$ & $47.8 \pm 5.0$ & $48.1 \pm 5.35$ & $47.7 \pm 4.8$ & .89 \\
\hline LVDs $(\mathrm{mm})$ & $31(28-34)$ & $31(28-35)$ & $31(28-34)$ & .85 \\
LA diameter $(\mathrm{mm})$ & $43(38-49)$ & $45(37-50)$ & $43(38-48.5)$ & .36 \\
\hline TRPG $(\mathrm{mm} \mathrm{Hg})$ & $21(17-26)$ & $21(17-27)$ & $21(17-25)$ & .67 \\
\%FS & $34.6 \pm 6.5$ & $34.4 \pm 6.2$ & $34.6 \pm 6.5$ & .89 \\
\hline TR grade $\geq 2$ & $47(12.6)$ & $16(10.2)$ & $31(14.2)$ & .57 \\
mPG (mm Hg) & $3(2.2-4)$ & $3(2-4)$ & $3(2.4-4)$ & .26 \\
\hline
\end{tabular}

Values are presented as $\mathrm{n}(\%)$, mean \pm standard deviation, or median (range). The anterior group was those patients with anterior leaflet prolapse including commissure leaflet prolapse, and the posterior group had posterior leaflet prolapse. MI, Mitral insufficiency; $L V D d$, left ventricular end-diastolic diameter; $L V D s$, left ventricular end-systolic diameter; $L A$, left atrial; $T R P G$, tricuspid regurgitant pressure gradient; $\% F S$, fractional shortening; $T R$, tricuspid regurgitation, $m P G$, mean transmitral pressure gradient.

most frequently ( $\mathrm{n}=231[81 \%]$ for both) in the posterior group. The full ring was selected more often for patients with an anterior lesion, and the partial band was selected more often in patients with a posterior lesion $(P<.0001)$.

Because more patients in the anterior group had atrial fibrillation and higher TR grade, concomitant maze procedure and tricuspid annuloplasty were performed significantly more frequently in the anterior group than in the posterior group $(P=.01$ and $P=.02$, respectively). Mean NYHA functional classification was significantly improved from 1.88 preoperatively to 1.02 postoperatively $(P=.01)$. Postoperative improvement in NYHA functional classification was not different between the anterior and the posterior groups $(P=.28)$.

TABLE 3. Mitral insufficiency (MI) $\geq 3$ at follow-up and the regurgitant jet site in full-ring versus partial-band repair

\begin{tabular}{|c|c|c|c|c|}
\hline & Total & $\begin{array}{l}\text { Partial band } \\
\quad(\mathbf{n}=\mathbf{3 0 3})\end{array}$ & $\begin{array}{l}\text { Full ring } \\
(\mathrm{n}=149)\end{array}$ & $P$ value \\
\hline $\mathrm{MI} \geqq 3$ at follow-up & 58 & $44(14.5)$ & $14(9.3)$ & .13 \\
\hline \multicolumn{5}{|l|}{ Site of regurgitant jet } \\
\hline Lateral & 18 & $13(4.2)$ & $5(3.3)$ & .63 \\
\hline Center & 19 & $12(3.9)$ & $7(4.6)$ & .7 \\
\hline Medial & 34 & $28(9.2)$ & $6(4.0)$ & .05 \\
\hline & \multicolumn{4}{|c|}{$\begin{array}{cc}\text { Anterior group } & \text { Anterior group } \\
(\mathbf{n}=\mathbf{7 2}) & (\mathbf{n}=\mathbf{9 4})\end{array}$} \\
\hline & \multicolumn{2}{|r|}{$16(22.2)$} & $4(4.2)$ & .0004 \\
\hline & \multicolumn{2}{|r|}{$\begin{array}{l}\text { Posterior group } \\
\quad(\mathbf{n}=\mathbf{2 3 1})\end{array}$} & \multicolumn{2}{|c|}{$\begin{array}{l}\text { Posterior group } \\
\quad(\mathbf{n}=\mathbf{5 4})\end{array}$} \\
\hline & \multicolumn{2}{|r|}{$12(5.2)$} & $2(3.7)$ & .64 \\
\hline
\end{tabular}

Values are presented as $\mathrm{n}(\%)$. The anterior group was those patients with anterior leaflet prolapse, including commissure leaflet prolapse, and the posterior group patients had posterior leaflet prolapse. $M I$, Mitral insufficiency. 
TABLE 4. Baseline characteristics of unmatched and matched patients between patients with partial-band and full-ring repair in the anterior group

\begin{tabular}{|c|c|c|c|c|c|c|c|c|}
\hline & \multicolumn{4}{|c|}{ Anterior $(n=167)$} & \multicolumn{4}{|c|}{ Matched patients } \\
\hline & Partial band & Full ring & $P$ value & $d$ & Partial band & Full ring & $P$ value & $d$ \\
\hline No. of patients & 73 & 94 & & & 59 & 59 & & \\
\hline Age $(y)$ & $60 \pm 13$ & $59 \pm 14$ & .88 & 0.07 & $56 \pm 13$ & $56 \pm 15$ & .78 & 0.001 \\
\hline Man & $46(63)$ & $63(67)$ & .58 & 0.08 & $42(71.1)$ & $41(69.5)$ & .84 & 0.04 \\
\hline $\operatorname{BSA}\left(\mathrm{m}^{2}\right)$ & $1.61 \pm 0.17$ & $1.62 \pm 0.19$ & .66 & 0.06 & $1.64 \pm 0.17$ & $1.63 \pm 0.17$ & .73 & 0.06 \\
\hline $\begin{array}{l}\text { NYHA functional class III or } \\
\text { IV }\end{array}$ & $5(6.8)$ & $5(5.3)$ & .67 & 0.06 & $3(5.1)$ & $2(3.4)$ & .64 & 0.08 \\
\hline Beta blocker & $7(9.5)$ & $22(23.4)$ & .015 & 0.38 & $7(11.9)$ & $8(13.6)$ & .78 & 0.05 \\
\hline $\mathrm{CCB}$ & $12(16.4)$ & $16(17.0)$ & .9 & 0.02 & $10(16.9)$ & $10(16.9)$ & 1 & 0.00 \\
\hline HT & $24(33.8)$ & $38(40.4)$ & .36 & 0.14 & $19(32.2)$ & $19(32.2)$ & 1 & 0.00 \\
\hline $\mathrm{HL}$ & $16(21.9)$ & $23(24.4)$ & .76 & 0.06 & $9(15.2)$ & $9(15.2)$ & 1 & 0.00 \\
\hline DM & $5(6.8)$ & $7(7.4)$ & .91 & 0.02 & $0(0)$ & $1(1.7)$ & .31 & 0.19 \\
\hline $\mathrm{FEV}_{1}<70 \%$ & $9(12.3)$ & $14(14.8)$ & .67 & 0.07 & $4(6.8)$ & $5(8.5)$ & .72 & 0.06 \\
\hline CRF on HD & $2(2.1)$ & 0 & .1 & 0.21 & 0 & 0 & & \\
\hline Af & $28(38.4)$ & $45(47.8)$ & .21 & 0.19 & $22(37.3)$ & $23(38.9)$ & .84 & 0.03 \\
\hline TR grade $>2$ & $10(13.7)$ & $26(27.6)$ & .02 & 0.35 & $9(15.2)$ & $10(16.9)$ & .8 & 0.05 \\
\hline CAD & $5(6.9)$ & $12(12.7)$ & .2 & 0.20 & $3(5.1)$ & $3(5.1)$ & 1 & 0.00 \\
\hline LVDd & $58.7 \pm 6.8$ & $58.0 \pm 6.2$ & .74 & 0.11 & $59.2 \pm 6.2$ & $59.1 \pm 5.6$ & .92 & 0.02 \\
\hline LAD & $51.3 \pm 10.0$ & $50.3 \pm 9.0$ & .55 & 0.11 & $50.5 \pm 10.0$ & $50.6 \pm 9.2$ & .89 & 0.01 \\
\hline$\% \mathrm{FS}$ & $39.8 \pm 7.3$ & $37.6 \pm 6.9$ & .058 & 0.31 & $38.4 \pm 6.0$ & $38.6 \pm 6.5$ & .85 & 0.03 \\
\hline Thyroid disorder & $6(8.2)$ & $3(3.2)$ & .14 & 0.22 & $2(3.4)$ & $2(3.4)$ & 1 & 0.00 \\
\hline
\end{tabular}

Values are presented as $\mathrm{n}$, mean \pm standard deviation, or $\mathrm{n}(\%) . d$, Standardized difference; $B S A$, body surface area; $N Y H A$, New York Heart Association; $C C B$, calcium channel blocker; $H T$, hypertension; $H L$, hyperlipidemia; $D M$, diabetes mellitus; $F E V_{l}$, forced expiratory volume in 1 second; $C R F$ on $H D$, chronic renal failure on hemodialysis; $A f$, atrial fibrillation; $T R$, tricuspid regurgitation; $C A D$, coronary artery disease; $L V D d$, left ventricular end-diastolic diameter; $L A D$, left atrial diameter; $\% F S$, fractional shortening.

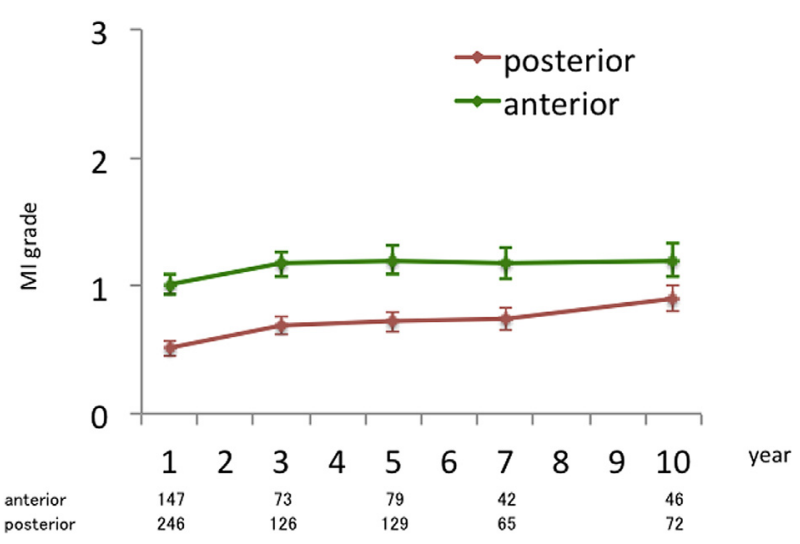

Anterior vs Posterior: $\mathrm{p}<0.0001$ Time: $P=0.0018$

Group $\times$ Time: $p=0.87$

FIGURE 1. Mitral insufficiency $(M I)$ severity between patients in the anterior group and those in the posterior group was shown throughout the follow-up period. There was significant difference in the MI severity between the anterior and the posterior groups $(P<.0001)$; however, there was no significant interaction between time and group $(P=.87)$.

\section{Long-Term Survival After Mitral Valve Repair}

Overall, 30-day mortality was $0.2 \%$. There was 1 in-hospital death caused by postoperative low-output syndrome in the anterior group, and none in the posterior group. There were 24 late deaths $(5 \%)$ during the follow-up: 10 in the anterior group and 14 in the posterior group (log-rank $P=.92)$. Ten were cardiac-related deaths, whereas 14 were noncardiac-related.

Kaplan-Meier analyses demonstrated 5- and 10-year survival to be $97.1 \%$ and $90.5 \%$, respectively, for all patients. Statistical analyses were also conducted to compare the survival between the anterior and the posterior groups (Figure E1). Survival at 5 and 10 years was not significantly different between the anterior and the posterior groups $(P=.92)$ (Figure E1). Moreover, survival in the anterior group or that in the posterior group was not significantly different between patients undergoing partial-band and full-ring repair (Figure E2).

\section{Partial Band for Anterior Lesion: The Worst Combination for MI Recurrence}

One-year follow-up echocardiography findings are shown in Table 2. MI grade decreased postoperatively in 


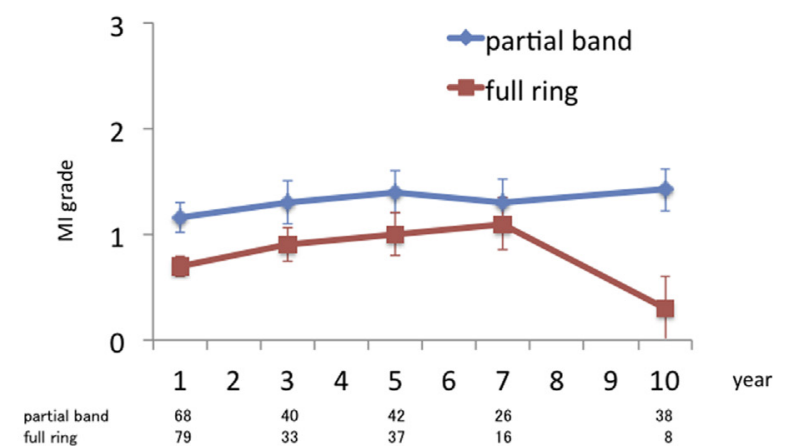

A

$$
\begin{gathered}
\text { partial vs full: } p=0.0176 \\
\text { Time: } p=0.027 \\
\text { Group } \times \text { Time: } p=0.35
\end{gathered}
$$

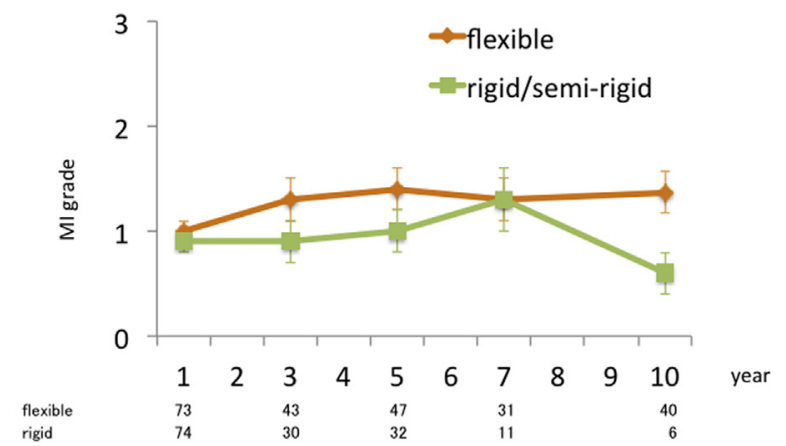

B

$$
\begin{gathered}
\text { flexible vs } \mathrm{rigid} / \mathrm{semi} \text {-rigid: } \mathrm{p}=0.051 \\
\text { Time: } \mathrm{p}=0.006 \\
\text { Group } \times \text { Time: } \mathrm{p}=0.776
\end{gathered}
$$

FIGURE 2. A, Mitral insufficiency $(M I)$ severity between patients undergoing partial-band and full-ring repair in the anterior lesion group was shown throughout the follow-up period. There was a significant difference in MI severity between the partial-band and the full-ring repair $(P=.0176)$; however, there was no significant interaction between time and group $(P=.35)$. B, MI severity of patients undergoing flexible-ring and rigid/semirigid-ring repair in the anterior group was shown throughout the follow-up period. There was no significant difference in MI severity between the flexible-ring and the rigid/semirigid-ring repair $(P=.051)$, and there was no significant interaction between time and group $(P=.776)$.

the anterior group and in the posterior group compared with the preoperative grade; however, MI grade at 1 year was significantly higher (ie, worse) in the anterior group than in the posterior group $(1.01$ vs $0.53 ; P<.0001)$. Median echocardiographic follow-up was 2.01 years, and the interquartile range of echocardiographic follow-up was 0.70 to 6.40 years. Because echocardiographic measures of MI severity were longitudinal data, the mixed-effect model with repeated measures was used to evaluate the association between MI severity and groups of patients, such as anterior versus posterior prolapse, full ring versus partial band in the anterior or posterior groups, or flexible ring versus rigid or semirigid ring in the anterior or posterior groups. Firstly, the

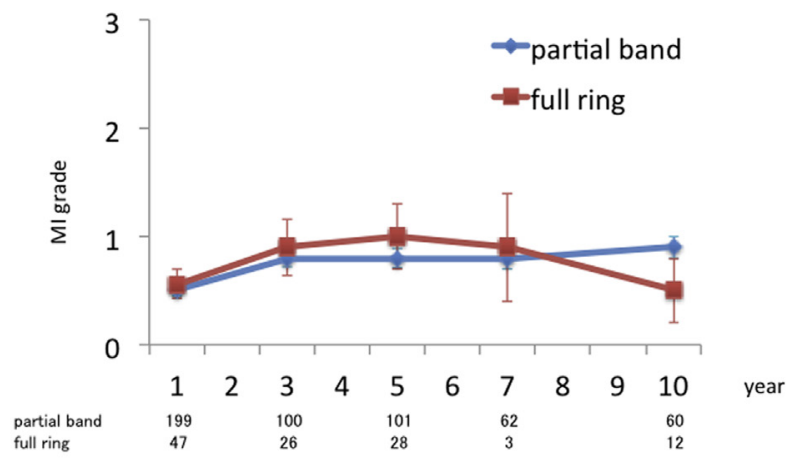

A

$$
\text { partial vs full: } p=0.42
$$

Time: $p<0.0001$

Group $\times$ Time: $p=0.74$

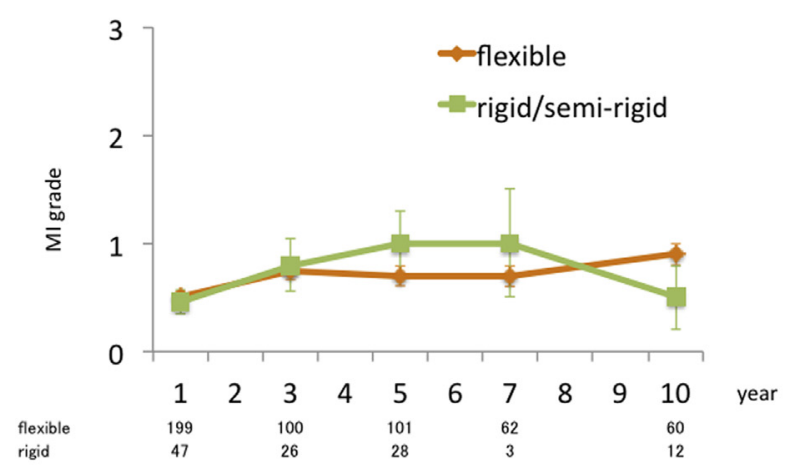

flexible vs rigid/semi-rigid: $p=0.94$

Time: $p<0.0001$

Group $\times$ Time: $\mathrm{p}=0.58$

\section{B}

FIGURE 3. A, Mitral insufficiency $(M I)$ severity between patients undergoing partial-band and full-ring repair in the posterior lesion group was shown throughout the follow-up period. There was no significant difference in MI severity between the partial-band and the flexible-ring repair $(P=.42)$, and there was no significant interaction between time and group $(P=.74)$. B, MI severity between patients undergoing flexible-ring and rigid/semirigid-ring repair in the anterior group was shown throughout the follow-up period. There was no significant difference in MI severity between the flexible-ring and the rigid/semirigid-ring repair $(P=.94)$, and there was no significant interaction between time and group $(P=.58)$

MI severity was compared between patients of the anterior group and the posterior group throughout the follow-up period (Figure 1). MI severity of the anterior group was higher than that of the posterior group over the study period $(P<.0001)$. MI severity significantly increased over time in both the anterior and posterior groups $(P=.0018)$; however, progression rate of MI severity was not statistically different between the anterior group $(0.037 \pm 0.011$ /year $)$ and the posterior group $(0.039 \pm 0.015$ /year; $P=.87)$.

Secondly, MI severity in the anterior group was compared between the partial band and the full ring, or flexible ring and rigid/semirigid ring throughout the follow-up 




$$
\begin{gathered}
\text { partial vs full: } p=0.04 \\
\text { Time: } p<0.0001 \\
\text { Group } \times \text { Time: } p=0.12
\end{gathered}
$$

FIGURE 4. Mitral insufficiency $(M I)$ severity between matched patients undergoing partial-band and full-ring repair in the anterior lesion group was shown throughout the follow-up period. There was a significant difference in MI severity between the partial-band and the full-ring repair $(P=.04)$; however, there was no significant interaction between time and group $(P=.12)$.

period (Figure 2). MI severity in patients undergoing partial-band repair was higher than in patients undergoing full-ring repair over time in the anterior group $(P=.0176)$. MI severity significantly increased over time in patients with partial-band and full-ring repair $(P=.027)$, without significant difference in the progression rate of MI severity between the partial-band $(0.031 \pm 0.013 /$ year) and the full-ring (0.05 $\pm 0.025 /$ year; $P=.35)$. In contrast, there was no significant deference in MI severity between patients with a flexible ring and a rigid/semirigid ring $(P=.051)$. MI severity significantly increased over time in patients with a flexible ring and a rigid/semirigid ring $(P=.006)$ without significant difference in the progression rate of MI severity between the flexible ring $(0.036 \pm 0.013 /$ year $)$ and the rigid/semirigid ring $(0.044 \pm 0.029 /$ year; $P=.776)$.

Finally, MI severity in the posterior group was compared between patients undergoing repair with a partial band and the full ring or the flexible and the rigid/semirigid ring throughout follow-up (Figure 3). In the posterior group, there was no significant difference in MI severity between the partial band and the full ring $(P=.42)$, or between the flexible ring and the rigid/semirigid ring $(P=.94)$. Consistently, there was no significant interaction between the partial-band versus full-ring groups and time $(P=.74)$, or between the flexible ring versus rigid/ semirigid ring groups and time $(P=.58)$.

\section{Propensity Score-Matched Analysis}

Although the mixed-effect model showed MI severity over time in patients with a partial-band repair was significantly higher than with full-ring repair in the anterior group but not in the posterior group, baseline characteristics were statistically different between patients undergoing the partial-band and the full-ring repair in the anterior group. Therefore, propensity-matched analysis was calculated with multiple logistic regression using the 18 variables (shown in Table 4), and obtained 59 well-matched patients pair with the $C$ statistics being 0.74 . After matching, the mixed-effect model was used to compare the partial-band and the full-ring repair in the matched patients of the anterior group.

MI severity in matched patients with a partial band was significantly higher than in patients with the full ring over time in the anterior group $(P=.04)$ (Figure 4$)$. In addition, MI severity significantly increased over time in both the matched patients undergoing partial-band and full-ring repair $(P<.0001)$; however, at a rate of $0.093 \pm 0.013 /$ year in the matched patients with partial-band repair and $0.058 \pm 0.022 /$ year in the matched patients with full-ring repair with no significant difference $(P=.12)$. Regarding the posterior group, similarly, propensity-matched analysis using 18 variables obtained 49 well-matched patient pairs with $C$ statistic being 0.75 , as shown in Table E4. A mixed-effect model using the matched patients showed no significant difference in MI severity over time between partial-band and full-ring repair $(P=.67)$ and no significant interaction between group (partial band vs full ring) and time $(P=.84)$, as shown in Figure E3.

\section{Regurgitant Jet From the Medial Side in the Partial- Band Repair}

$\mathrm{MI} \geq 3$ was detected in 58 patients on follow-up echocardiography. Regurgitant jet sites in these patients, assessed by echocardiography, were compared in patients undergoing partial-band versus full-ring repair (Table 3). MI $\geq 3$ was detected more frequently in patients undergoing partial-band repair, and the site of the regurgitant jet in these patients was lateral in 13 patients $(4.2 \%)$, central in 12 patients $(3.9 \%)$, and medial in 28 patients $(9.2 \%)$. In contrast, the site of the regurgitant jet in patients with a full ring was lateral in 5 patients $(3.3 \%)$, central in 7 patients $(4.6 \%)$, and medial in 6 patients $(4.0 \%)$. The number of patients who developed medial-side regurgitation was significantly greater in those undergoing partial-band repair compared with full-ring repair $(P=.05)$. Furthermore, when a partial band was used in patients with an anterior lesion, MI $\geq 3$ at follow-up was significantly more frequent on the medial side $(P=.0004)$.

\section{Exploring Predictive Factors of $\mathrm{MI} \geq \mathbf{3}$}

Echocardiographic measures of MI severity were longitudinal data. However, to explore risk factors for MI $\geq 3$, we treated MI $\geq 3$ as a time-related event. On follow-up echocardiography, MI $\geq 3$ at follow-up was 
detected in 58 patients ( 34 patients in the anterior group and 24 patients in the posterior group; $P=.0003$ ). Freedom from MI $\geq 3$ at follow-up at 5 and 10 years was $90.4 \%$ and $83.1 \%$, respectively, for all patients, and was significantly worse for the anterior group than for the posterior group at 5 and 10 years $(P=.002)$ (Figure E4). However, within the anterior group, freedom from $\mathrm{MI} \geq 3$ at follow-up was significantly better for full-ring than for partial-band repair (Figure E5, $A$ ), although this difference was not significant in the posterior group $(P=.7)$ (Figure E5, B). In the anterior group, the respective 5- and 10 -year freedoms from MI $\geq 3$ were $79.6 \%$ and $68.9 \%$ for partial band, and $88.2 \%$ and $80.2 \%$ for full ring repair $(P=.04$ for comparison of 10 -year freedom from MI $\geq 3$ between partial band vs full ring).

Predictive factors for recurrence of MI by univariate and multivariate analyses are shown in Table E5. Univariate analysis showed that anterior lesion, chordal replacement, and postoperative MI grade $\geq 2$ were significant predictive factors of MI $\geq 3$ at follow-up. Multivariate analysis showed that anterior lesion and postoperative MI grade $\geq 2$ were independent risk factors for $\mathrm{MI} \geq 3$ at follow-up. Next, we analyzed risk factors for recurrence of MI in those with the anterior lesion. Univariate and multivariate Cox hazard analysis using variables, including partial band, resection and suture, chordal replacement, and edge-to-edge repair, showed that use of a partial band was the single independent risk factor for MI $\geq 3$ at follow-up in the anterior group $(P=.0069$; hazard ratio, 2.82).

\section{Freedom From Reoperation and Risk Factors for Reoperation}

Causes of reoperation are shown in Table E6. During the follow-up period, reoperation was required in 21 patients; significantly more patients required reoperation in the anterior group $(\mathrm{n}=15[8.1 \%])$ compared with the posterior group $(\mathrm{n}=6[2.3 \%])(P=.0018)$. Freedom from reoperation at 5 and 10 years was $96.1 \%$ and $92.1 \%$, respectively, for all patients. Multivariate analysis revealed anterior lesion to be a significant predictor of reoperation (Table E5). Five- and 10-year freedom from reoperation was significantly lower in the anterior group than in the posterior group $(P=.0009)$ (Figure E6). Moreover, in the anterior group, freedom from reoperation at 5 and 10 years was not significantly different between patients undergoing partial-band and full-ring repair (log rank $P=.45$ ) (Figure $\mathrm{E} 7, A$ ). A similar result was obtained in the posterior groups (log rank $P=.94$ ) (Figure $\mathrm{E} 7, B$ ).

\section{DISCUSSION}

The principal findings of the present study were significantly higher MI severity over time and significantly lower freedom from reoperation in the anterior group than in the posterior group. Moreover, MI severity over time in patients undergoing partial-band repair was higher than in patients undergoing full-ring repair in the anterior group. The results of propensity score-matched analysis, which was not used for comparison between patients undergoing partial-band and full-ring repair in the anterior or the posterior group in previous studies, strongly suggested that MI severity over time in patients undergoing partialband repair was higher than patients undergoing full-ring repair in the anterior group. Kaplan-Meier methods or the Cox hazard model, which treated MI $\geq 3$ as a timerelated event, were used to ensure these principal findings.

The present results strongly support mitral valve repair for type II dysfunction, especially for isolated posterior prolapse, and are consistent with the results of several recent studies. ${ }^{7,16,17}$ However, repair for anterior prolapse with or without commissure lesion was not as durable as that for posterior prolapse. Spiegelstein and colleagues ${ }^{6}$ reported anterior leaflet prolapse, lack of annuloplasty, concomitant procedure, left ventricular dysfunction, advanced age, and higher NYHA class to be significant predictors of reoperation and recurrence of moderate to severe mitral regurgitation. ${ }^{7,17-19}$ David and colleagues ${ }^{7}$ reported that anterior prolapse was an independent predictor of valve-related mortality; they also reported higher rates of reoperation for anterior than for posterior prolapse $(28 \% \pm 7 \%$ vs $11 \% \pm 3 \%$, respectively, at 15 years). Therefore, any modification of repair should be considered for anterior prolapse. The repair technique used most frequently for anterior prolapse in the present study was chordal replacement using polytetrafluoroethylene sutures, ${ }^{20}$ which is an established technique. ${ }^{21,22}$ In the present study, multivariate analysis showed that leaflet repair procedure was not an independent risk factor for MI $\geq 3$ at follow-up. Thus, we focused on prosthesis, and found that MI severity over time in patients undergoing partial-band repair was higher than in patients undergoing repair with a full ring in the anterior group, but not in the posterior group. Although the optimal choice of annuloplasty ring type continues to be debated, the present study suggests that full ring is the optimal choice for anterior prolapse. Several studies have examined the effect of annuloplasty type on repair durability, left ventricular function, and functional mitral stenosis after primary mitral repair, ${ }^{23}$ but the structure of the prosthesis applied has not been extensively discussed. Spiegelstein and colleagues ${ }^{6}$ reported that the use of open annuloplasty rings is an independent predictor of late recurrence of moderate or severe mitral regurgitation. Closed semirigid rings may increase the length of leaflet coaptation compared with open flexible rings and thus minimize the recurrence of significant mitral regurgitation. ${ }^{11}$ In the present study, the 1-to-1 matched analysis eliminating the effects of differences in patient characteristics also showed that MI severity over time in patients undergoing partial-band repair was higher than in patients undergoing repair with a full ring in the anterior group. These results 
show that using full-ring repair for an anterior lesion decreased MI severity over time and limited chances of recurrent MI.

The present results suggest another aspect of MI recurrence when partial-band repair is used for anterior prolapse. In the anterior group, regurgitant jet occurred significantly more frequently on the medial side in patients receiving a partial band than in those undergoing full-ring repair. Therefore, the use of a full ring may contribute to reducing the occurrence of regurgitant medial-side jet. As we previously reported, ${ }^{24}$ left ventricular remodeling may be associated with the recurrence of MI and tethering in addition to recurrence of prolapse, which can be a cause of recurrent MI. The anatomic characteristics of medial chordae make them more likely to be influenced by geometry change. Regardless of whether the mechanism of recurrent MI was leaflet prolapse or tethering (Table E6), using a full ring may help to keep the mitral annulus in its original form. However, no study has yet investigated the association between recurrent MI and regurgitant jet site; further studies are warranted to investigate the relationship between site of MI recurrence and prosthesis type.

Although the closed, rigid ring was reported to impair the natural motion of the mitral valve, distort the anterior leaflet, reduce orifice area, increase gradient across the valve, and increase the risk of systolic anterior motion, ${ }^{25-27}$ in the present study we found no differences in pressure gradient across the valve and prevalence of systolic anterior motion between full-ring and partial-band repairs.

\section{Limitations}

This was a retrospective, nonrandomized study with a limited follow-up period. Although MI $\geq 3$ at follow-up is not an event detected on echocardiography at a given time but interval-censored data, broadly used simple time-toevent analysis was partially selected for this research. There are limitations to propensity score-matched analyses. Eighteen variables about patient background and preoperative characteristics included in this analysis are believed to be small size. However, variables strongly related to outcome, such as preoperative echocardiographic findings, were included in 18 variables. Furthermore, only 59 matched patient pairs from 18 variables were obtained because of small patient numbers, so we used this model. Although there were significantly fewer cases with $\mathrm{MI} \geq 3$ at follow-up in those with full-ring versus partial-band repair in the anterior group, there was no corresponding difference in reoperation rate in that group. However, recurrent MI and reoperation were not associated with long-term mortality in this study. Further follow-up of this series is warranted. In addition, one may claim that the 3-year echocardiography results were studied only in $60 \%$ of the total patients, leading to selection and/or recording bias for the statistical analysis. This potential bias would be minimal because the backgrounds or procedure details of patients who did not enter the statistical analysis were not different from those who were statistically analyzed and because survival or adverse events, including reoperation, were not different between them.

\section{CONCLUSIONS}

Mitral valve repair for patients with MI due to type II dysfunction is a recommended strategy that results in low rates of operative death, good long-term survival, and excellent freedom from recurrence and reoperation. Impairment of long-term durability of mitral valve repair in patients with anterior prolapse can be compensated for by performing full-ring annuloplasty rather than partial-band annuloplasty.

\section{Conflict of Interest Statement}

Authors have nothing to disclose with regard to commercial support.

\section{References}

1. Avierinos JF, Gersh BJ, Melton LJ III, Bailey KR, Shub C, Nishimura RA, et al. Natural history of asymptomatic mitral valve prolapse in the community. Circulation. 2002;106:1355-61

2. Mohty D, Orszulak TA, Schaff HV, Avierinos JF, Tajik JA, Enriquez-Sarano M Very long-term survival and durability of mitral valve repair for mitral valve prolapse. Circulation. 2001;104:I1-7.

3. Gillinov AM, Cosgrove DM, Blackstone EH, Diaz R, Arnold JH, Lytle BW, et al. Durability of mitral valve repair for degenerative disease. J Thorac Cardiovasc Surg. 1998;116:734-43.

4. Suri RM, Schaff HV, Dearani JA, Sundt TM III, Daly RC, Mullany CJ, et al. Survival advantage and improved durability of mitral repair for leaflet prolapse subsets in the current era. Ann Thorac Surg. 2006;82:819-26.

5. Carpentier A. Cardiac valve surgery-the "French correction." J Thorac Cardiovasc Surg. 1983;86:323-37.

6. Spiegelstein D, Sternik L, Orlov B, Shinfeld A, Feinberg MS, Malachy A, et al. Mitral valve repair: isolated posterior compared to anterior or bileaflet pathology. J Card Surg. 2013;28:89-96.

7. David TE, Ivanov J, Armstrong S, Christie D, Rakowski H. A comparison of outcomes of mitral valve repair for degenerative disease with posterior, anterior, and bileaflet prolapse. J Thorac Cardiovasc Surg. 2005; 130:1242-9.

8. DiBardino DJ, ElBardissi AW, McClure RS, Razo-Vasquez OA, Kelly NE, Cohn LH. Four decades of experience with mitral valve repair: analysis of differential indications, technical evolution, and long-term outcome. J Thorac Cardiovasc Surg. 2010;139:76-83; discussion 83-4.

9. Gillinov AM, Blackstone EH, Alaulaqi A, Sabik JF III, Mihaljevic T, Svensson LG, et al. Outcomes after repair of the anterior mitral leaflet for degenerative disease. Ann Thorac Surg. 2008;86:708-17.

10. Kawamoto N, Fujita T, Hata H, Shimahara Y, Sato S, Kobayashi J Prosthesis-patient mismatch due to small ring annuloplasty in patients with degenerative mitral insufficiency. J Cardiol. 2016;68(2):141-7.

11. Spiegelstein D, Moshkovits Y, Sternik L, Fienberg MS, Kogan A, Malachy A, et al. Midterm results of mitral valve repair: closed versus open annuloplasty ring. Ann Thorac Surg. 2010;90:489-95.

12. Grewal J, Suri R, Mankad S, Tanaka A, Mahoney DW, Schaff HV, et al Mitral annular dynamics in myxomatous valve disease (new insight with real-time 3-dimentional echocardiography). Circulation. 2010;121: 1423-31.

13. Bothe W, Rausch MK, Kvitting JPE, Echtner DK, Walther M, Ingels NB, et al How do annuloplasty rings affect mitral annular strains in the normal beating ovine heart? Circulation. 2012;126(Suppl 1):S231-8. 
14. Chandra S, Salgo IS, Sugeng L, Weinert L, Tsang W, Takeuchi M, et al. Characterization of degenerative mitral valve disease using morphologic analysis of real-time three-dimensional echocardiographic images: objective insight into complexity and planning of mitral valve repair. Circ Cardiovasc Imag. 2011;4: 24-32.

15. Devereux RB, Reichek N. Echocardiographic determination of left ventricular mass in man. Anatomic validation of the method. Circulation. 1977;55:613-8.

16. Miura T, Eishi K, Yamachika S, Hashizume K, Yamane K, Taniguchi S, et al. Mitral valve repair for degenerative disease with leaflet prolapse: to improve long-term outcomes. Gen Thorac Cardiovasc Surg. 2009;57:10-21.

17. Stevens LM, Basmadjian AJ, Bouchard D, El-Hamamsy I, Demers P, Carrier M, et al. Late echocardiographic and clinical outcomes after mitral valve repair for degenerative disease. J Card Surg. 2010;25:9-15.

18. Chenot F, Montant P, Vancraeynest D, Pasquet A, Gerber B, Noirhomme PH, et al. Long-term clinical outcome of mitral valve repair in asymptomatic severe mitral regurgitation. Eur J Cardiothorac Surg. 2009;36:539-45.

19. Gillinov AM, Cosgrove DM. Mitral valve repair for degenerative disease. J Heart Valve Dis. 2002;11(Suppl):S15-20.

20. Hata H, Fujita T, Shimahara Y, Sato S, Ishibashi H, Kobayashi J. A 25-year study of chordal replacement with expanded polytetrafluoroethylene in mitral valve repair. Interact Cardiovasc Thorac Surg. 2015;20:463-9.

21. David TE, Armstrong S, Sun Z. Replacement of chordae tendineae with Gore-Tex sutures: a ten-year experience. J Heart Valve Dis. 1996;5:352-5.
22. Ibrahim M, Rao C, Athanasiou T. Artificial chordae for degenerative mitral valve disease: critical analysis of current techniques. Interact Cardiovasc Thorac Surg. 2012;15:1019-32.

23. Murashita T, Greason KL, Suri RM, Daly RC, Joyce LD, Stulak JM, et al. Mitral valve gradient after valve repair of degenerative regurgitation with restrictive annuloplasty. J Thorac Cardiovasc Surg. 2016;151: $106-9$

24. Fujita T, Kobayashi J, Toda K, Nakajima H, Iba Y, Shimahara Y, et al. Long-term outcome of combined valve repair and maze procedure for nonrheumatic mitral regurgitation. J Thorac Cardiovasc Surg. 2010;140:1332-7.

25. Kupferschmid JP, Carr T, Connelly GP, Shemin RJ. Systolic anterior motion of the mitral valve after valve repair without an annular ring. Ann Thorac Surg. 1994:57:484-6.

26. Lopez JA, Schnee M, Gaos CM, Wilansky S. Left ventricular outflow tract obstruction and hemolytic anemia after mitral valve repair with a Duran ring. Ann Thorac Surg. 1994;58:876-7; discussion 877-8.

27. Bothe W, Kuhl E, Kvitting JE, Rausch MK, Göktepe S, Swanson JC, et al. Rigid, complete annuloplasty rings increase anterior mitral leaflet strains in the normal beating ovine heart. Circulation. 2011;124(11 Suppl):S81-96.

Key Words: mitral valve repair, anterior lesion, partial band, mixed-effect model, propensity score matching

Readers who found these articles interesting may also like to read the following papers found in recent and future issues of our sister publications, Seminars in Thoracic and Cardiovascular Surgery and Operative Techniques in Thoracic and Cardiovascular Surgery!

\section{Acquired: Mitral Valve}

ORIGINAL SUBMISSION: Assessment of Mitral Valve Repair With Exercise Echocardiography: Artificial Chordae vs Leaflet Resection Sigurdur Ragnarsson. Semin Thoracic Surg 2017: 25-32.

Editorial Commentary: The Dance of 2 Devils: Mitral Valve Repair and Functional Mitral Stenosis Bobby Yanagawa. Semin Thoracic Surg 2017: 33-34.

ORIGINAL SUBMISSION: Comparative Histopathological Analysis of Mitral Valves in Barlow Disease and Fibroelastic Deficiency Jesper Hjortnaes. Semin Thoracic Surg 2016: 757-767.

Editorial Commentary: Angel in the Architecture and the Devil in the Details: Comparative Ultrastructure of Degenerative Mitral Valve Disease Tomasz A. Timek. Semin Thoracic Surg 2016: 768-769.

CURRENT READINGS: Similar Survival After Repair vs Replacement for Ischemic Mitral Regurgitation Hisato Takagi. Semin Thoracic Surg 2016: 748-756. 


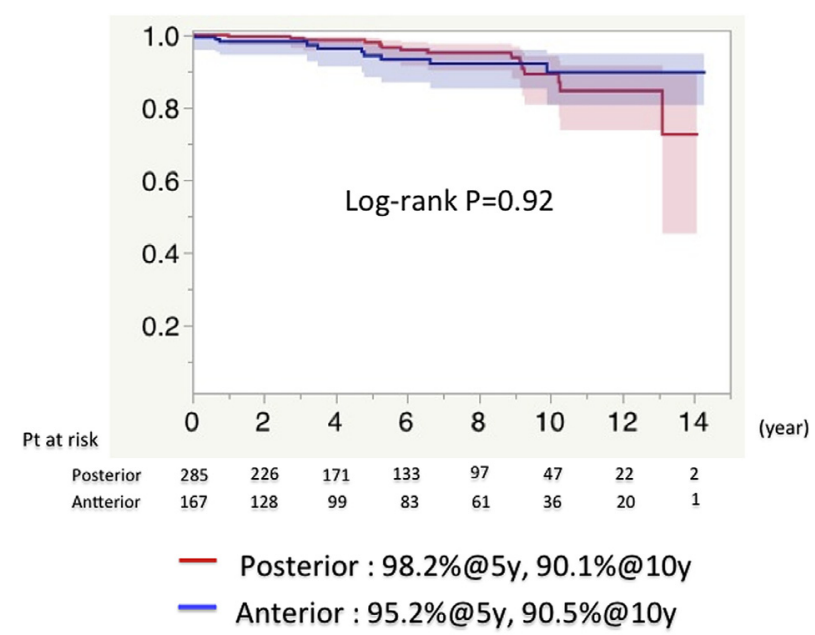

FIGURE E1. Five- and 10-year survival did not differ significantly between the anterior $(95.2 \%$ and $90.5 \%$, respectively) and posterior group ( $98.2 \%$ and $90.1 \%$, respectively) $(P=.92) . P t$, Patient.

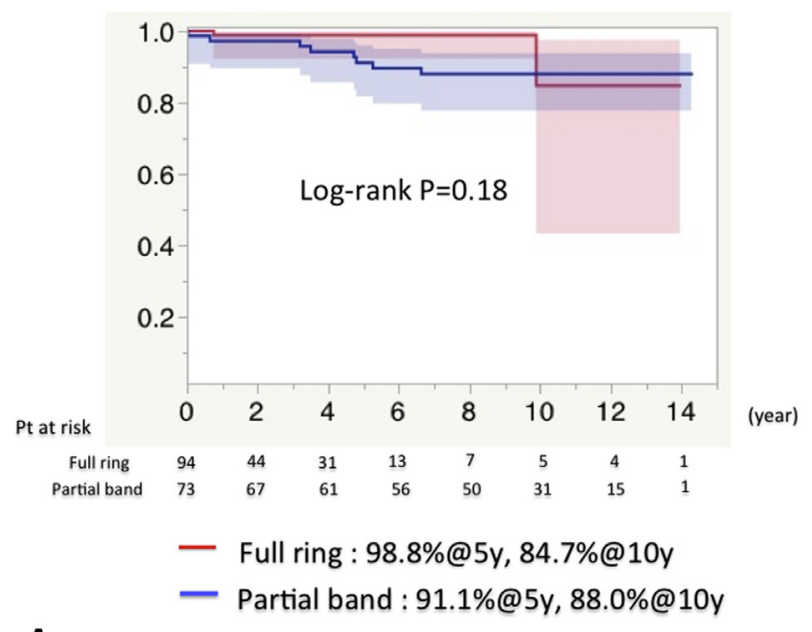

A

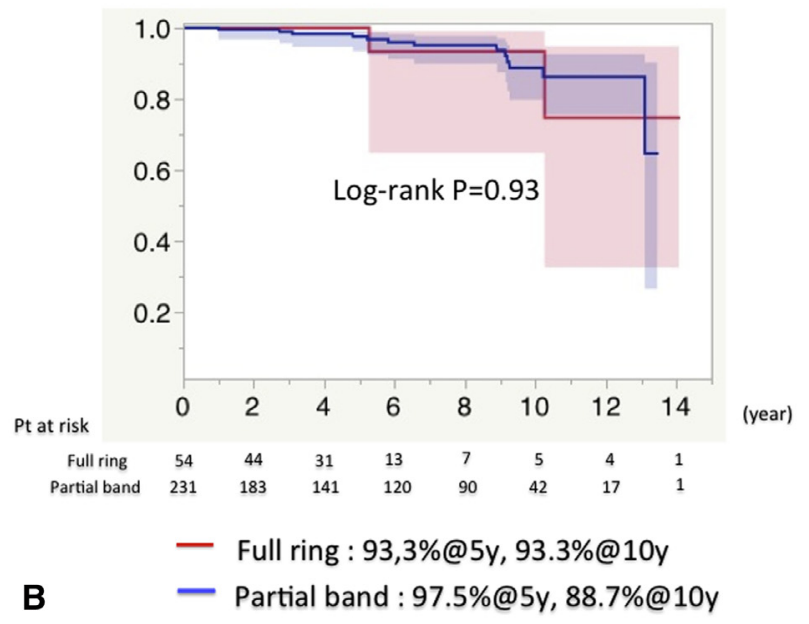

FIGURE E2. A, In the anterior group, 5- and 10-year survival did not differ significantly between partial-band $(91.1 \%$ and $88.0 \%$, respectively) and full-ring repair $(98.8 \%$ and $84.7 \%$, respectively) $(P=.18)$. B, In the posterior group, 5- and 10-year survival did not differ significantly between partial-band (97.5\% and $88.7 \%$, respectively) and full-ring repair $(93.3 \%$ and $93.3 \%$, respectively $(P=.93)$. Pt, Patient. 


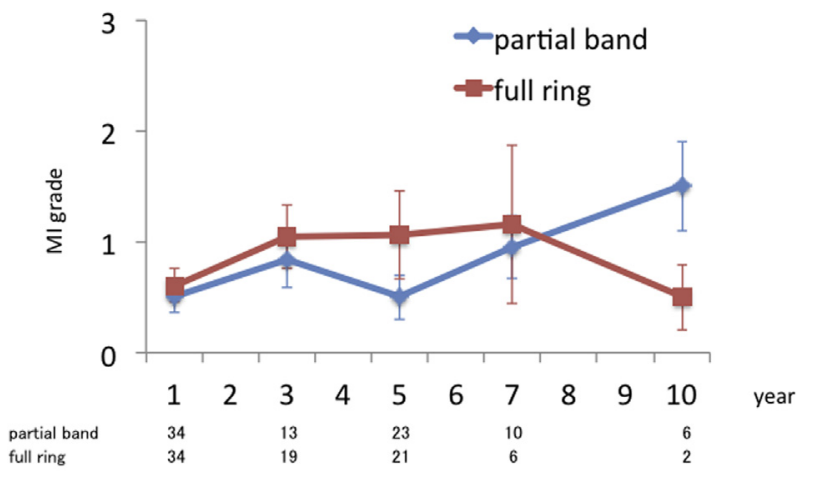

partial vs full: $p=0.67$
Time: $p=0.017$

Group $\times$ Time: $p=0.84$

FIGURE E3. The mitral insufficiency $(M I)$ severity of the matched patients with the partial-band and full-ring repair in posterior group was shown throughout the follow-up period. There was no significant difference in MI severity between the partial-band and the full-ring repair $(P=.67)$, and, there was no significant interaction between time and group $(P=.84)$.

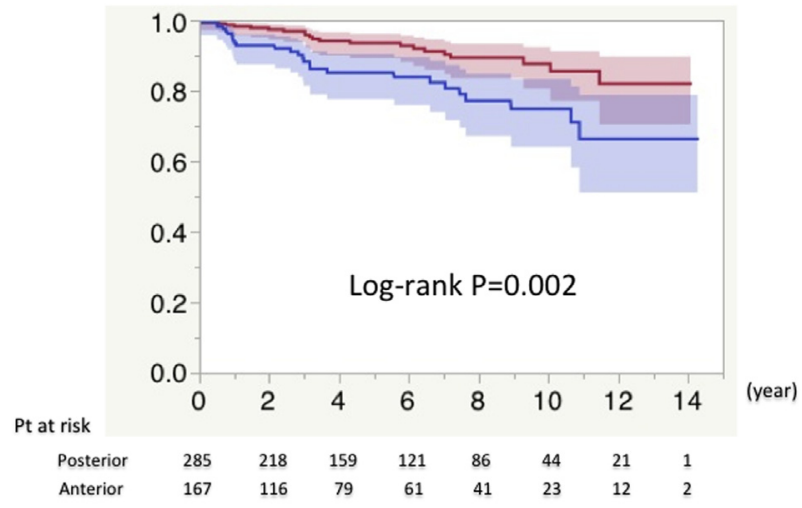

\section{— Posterior : 93.3\%@5y, 87.0\%@10y —Anterior : 85.1\%@5y, 74.5\%@10y}

FIGURE E4. Five- and 10-year freedom from MI $\geq 3$ was significantly lower in the anterior $(85.1 \%$ and $74.5 \%$, respectively) versus the posterior group $(93.3 \%$ and $87.0 \%$, respectively) $(P=.002)$. $P t$, Patient.

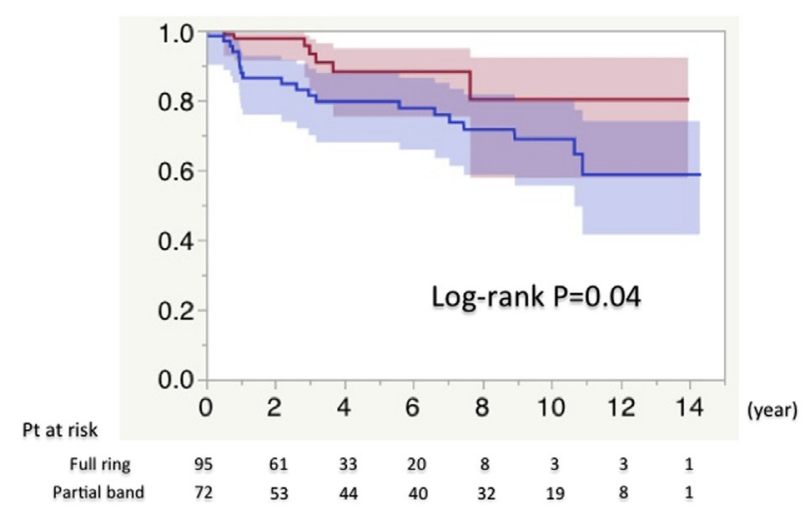

— Full ring: 88.2\%@5y, 80.2\%@10y

— Partial band: 79.6\%@5y, 68.9\%@10y

A

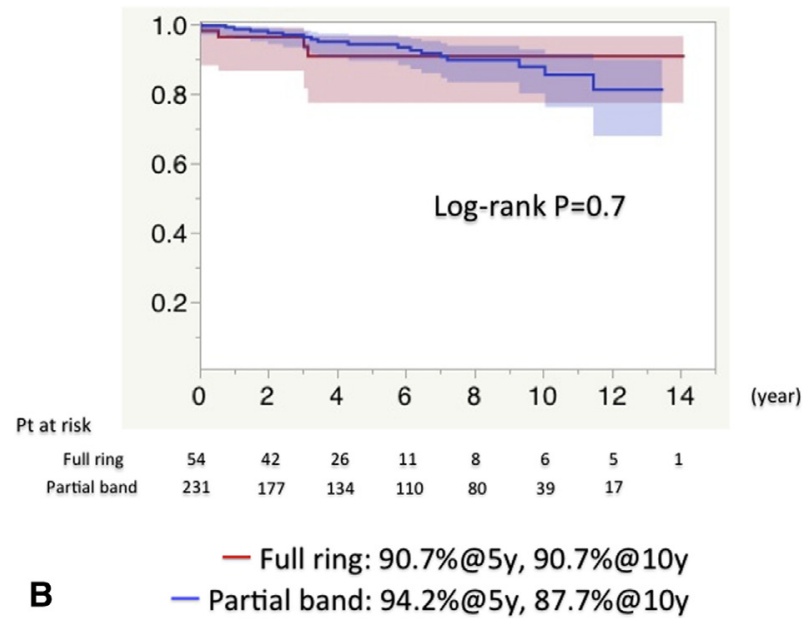

FIGURE E5. A, In the anterior group, patients with partial-band repair had higher rates of mitral insufficiency $\geq 3$ at follow-up compared with full ring repair $(P=.04)$. B, In the posterior group, there was no significant difference in mitral insufficiency $\geq 3$ at follow-up between full-ring and partial-band repair $(P=.7)$. $P t$, Patient.

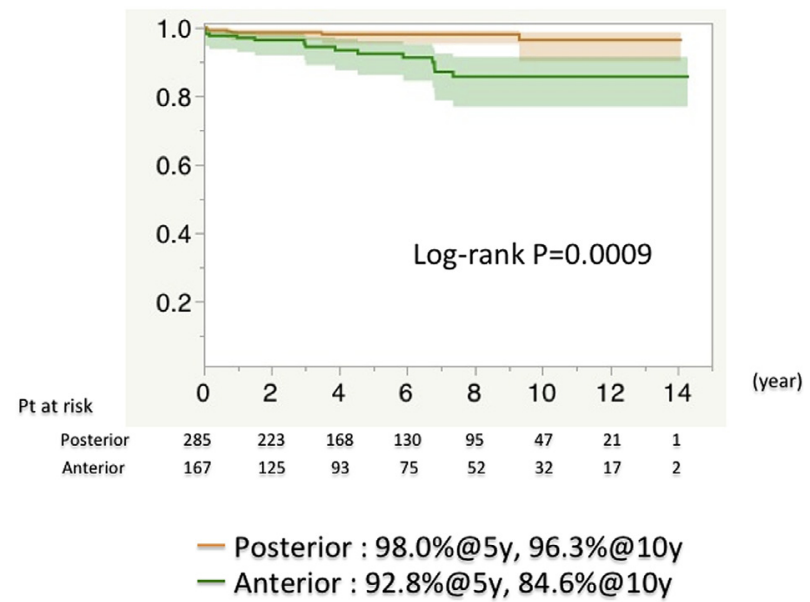

FIGURE E6. Five- and 10-year freedom from reoperation was significantly lower in the anterior ( $92.8 \%$ and $84.6 \%$, respectively) than in the posterior group $(98.0 \%$ and $96.3 \%$, respectively) $(P=.006)$. Pt, Patient. 


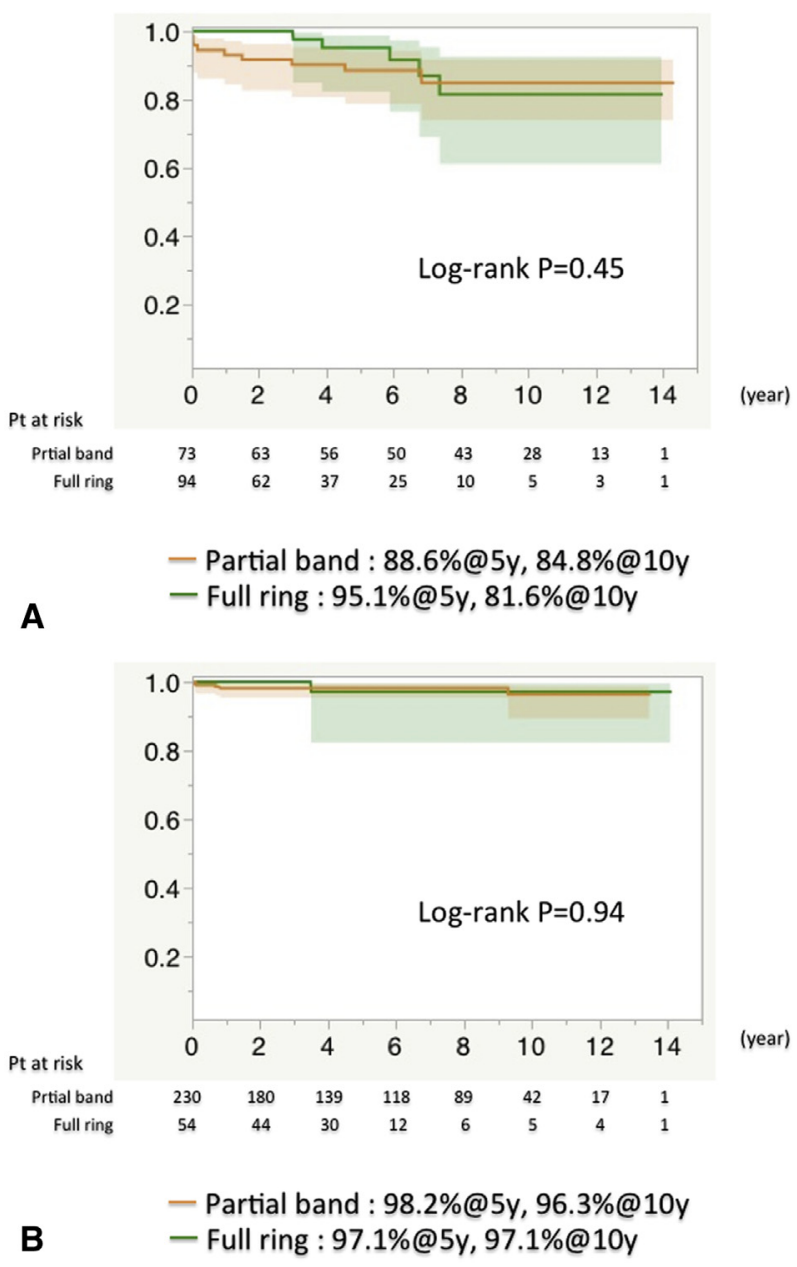

FIGURE E7. A, In the anterior group, 5- and 10-year freedom from reoperation did not differ significantly in patients with partial-band $(88.6 \%$ and $84.8 \%$, respectively) versus full-ring repair $(95.1 \%$ and $81.6 \%$, respectively) $(P=.45)$. B, In the posterior group, 5 - and 10-year freedom from reoperation did not differ significantly in patients with partial-band $(98.2 \%$ and $86.3 \%$, respectively) versus full-ring repair (97.1\% and $97.1 \%$, respectively) $(P=.94) . P t$, Patient.

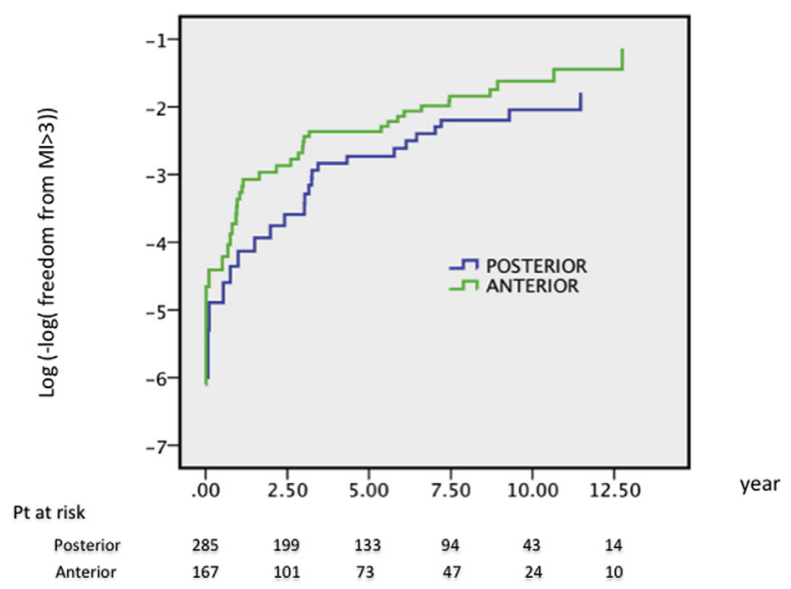

A

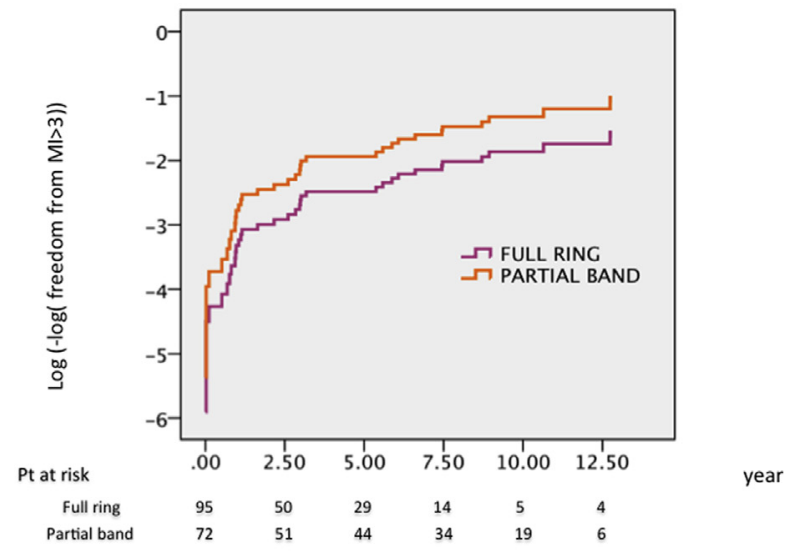

B

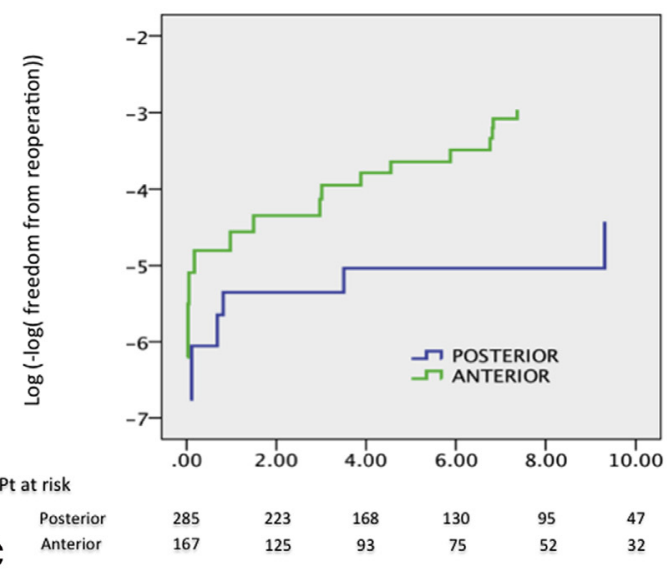

FIGURE E8. A, The graph of $\log (-\log [$ freedom from mitral insufficiency $(M I) \geq 3]$ ) versus time for group (anterior or posterior). Log of minus the $\log$ versus time graph resulted in parallel curve. B, The graph of $\log (-\log$ [freedom from MI $\geq 3$ ]) versus time for group (partial band or full ring in anterior group). Log of minus the log versus time graph resulted in parallel curve. C, The graph of $\log (-\log [$ freedom from reoperation] $)$ versus time for group (anterior or posterior prolapse). Log of minus the log versus time graph resulted in parallel curve. Pt, Patient. 
TABLE E1. Follow-up echocardiographic findings at 1 year, 3 years, 5 years, and 10 years

\begin{tabular}{lcccc}
\hline & \multicolumn{4}{c}{ Year } \\
\cline { 2 - 5 } & $\mathbf{1}(\mathbf{n}=\mathbf{3 7 3})$ & $\mathbf{3}(\mathbf{n}=\mathbf{1 9 7})$ & $\mathbf{5}(\mathbf{n}=\mathbf{2 1 3})$ & $\mathbf{1 0}(\mathbf{n}=\mathbf{1 1 8})$ \\
\hline MI grade $\geq 2$ & $49(13.1)$ & $44(22.3)$ & $50(23.4)$ & $33(27.9)$ \\
LVDd $(\mathrm{mm})$ & $47.8 \pm 5.0$ & $48.1 \pm 5.2$ & $48.3 \pm 5.2$ & $49.5 \pm 5.7$ \\
LVDs $(\mathrm{mm})$ & $31.2 \pm 3.0$ & $31.3 \pm 5.3$ & $31.5 \pm 5.4$ & $33.1 \pm 5.9$ \\
LAD $(\mathrm{mm})$ & $43.5 \pm 6.0$ & $46.4 \pm 9.3$ & $46.8 \pm 8.9$ & $47.5 \pm 9.3$ \\
TRPG $(\mathrm{mm} \mathrm{Hg})$ & $21.0 \pm 4.5$ & $23.3 \pm 8.3$ & $23.4 \pm 9.3$ & $24.9 \pm 7.1$ \\
\%FS & $34.6 \pm 6.5$ & $35.3 \pm 6.5$ & $34.8 \pm 6.5$ & $33.2 \pm 6.5$ \\
TR $($ grade $)$ & $0.77 \pm 0.8$ & $0.86 \pm 0.8$ & $0.92 \pm 0.92$ & $1.14 \pm 0.91$ \\
mPG $(\mathrm{mm} \mathrm{Hg})$ & $3.0 \pm 0.9$ & $3.6 \pm 1.4$ & $3.6 \pm 1.5$ & $3.8 \pm 1.8$ \\
\hline Va
\end{tabular}

Values are presented as $\mathrm{n}(\%)$ or mean \pm standard deviation. $M I$, Mitral insufficiency; $L V D d$, left ventricular end-diastolic diameter; $L V D s$, left ventricular end-systolic diameter; $L A D$, left atrial diameter; TRPG, tricuspid regurgitant pressure gradient; $\% F S$, fractional shortening; $T R$, tricuspid regurgitation; $m P G$, mean transmitral pressure gradient.

TABLE E2. Characteristics and echocardiography findings in followed and not-followed patients at 3 years

\begin{tabular}{|c|c|c|c|}
\hline & $\begin{array}{c}\text { Followed } \\
\text { patients } \\
(n=197)\end{array}$ & $\begin{array}{c}\text { Not-followed } \\
\text { patients } \\
(n=134)\end{array}$ & $\begin{array}{c}P \\
\text { value }\end{array}$ \\
\hline Age (y) & $59 \pm 12$ & $61 \pm 11$ & .1 \\
\hline Men & $106(53)$ & $89(66)$ & .02 \\
\hline $\operatorname{BSA}\left(\mathrm{m}^{2}\right)$ & $1.62 \pm 0.17$ & $1.62 \pm 0.19$ & .85 \\
\hline Af & $73(37)$ & $40(29)$ & .19 \\
\hline \multicolumn{4}{|c|}{ Preoperative echocardiography findings } \\
\hline MI grade & $3.81 \pm 0.36$ & $3.75 \pm 0.40$ & .2 \\
\hline LVDd (mm) & $58.3 \pm 6.4$ & $58.4 \pm 6.3$ & .86 \\
\hline LVDs (mm) & $35.9 \pm 6.6$ & $58.1 \pm 6.7$ & .48 \\
\hline $\mathrm{LAD}(\mathrm{mm})$ & $51.7 \pm 9.2$ & $49.7 \pm 7.9$ & .11 \\
\hline TRPG (mm Hg) & $33.1 \pm 14.9$ & $32.6 \pm 13.6$ & .92 \\
\hline$\% \mathrm{FS}$ & $38.5 \pm 6.5$ & $39.2 \pm 7.0$ & .85 \\
\hline TR (grade) & $1.19 \pm 0.9$ & $1.19 \pm 0.9$ & .98 \\
\hline Posterior prolapse & $115(58)$ & $82(61 \%)$ & .59 \\
\hline \multicolumn{4}{|l|}{ Repair technique } \\
\hline Partial band & $132(67)$ & $93(69 \%)$ & .63 \\
\hline Flexible ring/band & $137(69)$ & $96(71)$ & .58 \\
\hline Resection and suture & $142(72)$ & $91(67)$ & .36 \\
\hline Chordal replacement & $56(28)$ & $38(28)$ & .98 \\
\hline Edge to edge & $34(17)$ & $17(12)$ & .25 \\
\hline \multicolumn{4}{|l|}{ Concomitant procedure } \\
\hline Maze & $56(28)$ & $36(26)$ & .74 \\
\hline TAP & $28(14)$ & $19(14)$ & .98 \\
\hline CABG & $8(4)$ & $11(8.2)$ & .11 \\
\hline Other & $8(4)$ & $5(3.7)$ & .59 \\
\hline
\end{tabular}

Values are presented as mean \pm standard deviation or $\mathrm{n}(\%) . B S A$, Body surface area; $A f$, atrial fibrillation; $M I$, mitral insufficiency; $L V D d$, left ventricular end-diastolic diameter; $L V D s$, left ventricular end-systolic diameter; $L A D$, left atrial diameter; $T R P G$, tricuspid regurgitant pressure gradient; $\% F S$, fractional shortening; $T R$, tricuspid regurgitation; $T A P$, tricuspid annuloplasty; $C A B G$, coronary artery bypass grafting.
TABLE E3. Normality distribution of the continuous variables using Shapiro-Wilk test

\begin{tabular}{llcc}
\hline & \multicolumn{3}{c}{$P$ value (Shapiro-Wilk test) } \\
\cline { 2 - 4 } & All & Anterior & Posterior \\
\hline $\begin{array}{l}\text { Left ventricular end-diastolic } \\
\quad \text { diameter }\end{array}$ & .448 & .39 & .547 \\
Left anterior descending & .014 & .076 & .03 \\
$\begin{array}{l}\text { Tricuspid regurgitant pressure } \\
\text { gradient }\end{array}$ & .0001 & .0001 & .0001 \\
\% Fractional shortening & .005 & .081 & .049 \\
Age & .001 & .01 & .009 \\
$\begin{array}{l}\text { Body surface area } \\
\text { 1-y Left ventricular end-diastolic }\end{array}$ & .244 & .288 & .381 \\
$\quad$ diameter & & .218 & .44 \\
$\begin{array}{l}\text { 1-y Left ventricular end-systolic } \\
\text { diameter }\end{array}$ & .002 & .088 & .015 \\
\hline 1-y Left atrial diameter & .004 & .02 & .0001 \\
$\begin{array}{l}\text { 1-y Tricuspid regurgitant pressure } \\
\text { gradient }\end{array}$ & .0001 & .0001 & .03 \\
\hline $\begin{array}{l}\text { 1-y Mean transmitral pressure } \\
\text { gradient }\end{array}$ & .0001 & .0001 & .0001 \\
\hline 1-y \% Fractional shortening & .568 & .893 & .572 \\
\hline
\end{tabular}


TABLE E4. Baseline characteristics of unmatched and matched patients between patients with partial-band and full-ring repair in the posterior group

\begin{tabular}{|c|c|c|c|c|c|c|c|c|}
\hline & \multicolumn{4}{|c|}{ Posterior group $(n=285)$} & \multicolumn{4}{|c|}{ Matched patients } \\
\hline & Partial band & Full ring & $P$ value & $d$ & Partial band & Full ring & $P$ value & $\bar{d}$ \\
\hline No. of patients & 231 & 54 & & & 49 & 49 & & \\
\hline Age $(y)$ & $60 \pm 11$ & $59 \pm 13$ & .65 & 0.08 & $58 \pm 12$ & $59 \pm 12$ & .65 & 0.08 \\
\hline Man & $144(62)$ & $45(83)$ & .0021 & 0.48 & $38(77)$ & $40(82)$ & .61 & 0.12 \\
\hline $\operatorname{BSA}\left(\mathrm{m}^{2}\right)$ & $1.63 \pm 0.20$ & $1.64 \pm 0.17$ & .85 & 0.05 & $1.62 \pm 0.19$ & $1.64 \pm 0.17$ & .85 & 0.11 \\
\hline $\begin{array}{l}\text { NYHA functional class III or } \\
\text { IV }\end{array}$ & $17(7.3)$ & $8(14.8)$ & .1 & 0.24 & $3(6.1)$ & $5(10.2)$ & .45 & 0.15 \\
\hline Beta blocker & $31(13.4)$ & $10(18.5)$ & .37 & 0.14 & $8(16.3)$ & $9(18.3)$ & .78 & 0.05 \\
\hline $\mathrm{CCB}$ & $47(20.3)$ & $10(18.5)$ & .72 & 0.05 & $11(22.4)$ & $9(16.9)$ & .61 & 0.14 \\
\hline HT & $104(45)$ & $20(37)$ & .29 & 0.16 & $18(36.7)$ & $19(38.8)$ & .83 & 0.04 \\
\hline HL & $59(25.5)$ & $10(18.5)$ & .27 & 0.17 & $6(12.2)$ & $9(18.3)$ & 39 & 0.17 \\
\hline DM & $29(12.5)$ & $4(7.4)$ & .27 & 0.17 & $2(4.1)$ & $4(8.1)$ & .39 & 0.17 \\
\hline $\mathrm{FEV}_{1}<70 \%$ & $24(10.3)$ & $4(7.4)$ & .5 & 0.10 & $4(8.1)$ & $4(8.1)$ & 1 & 0.00 \\
\hline CRF on HD & 0 & 0 & & & 0 & 0 & & \\
\hline Af & 66 (28.7) & $24(44.4)$ & .025 & 0.33 & $22(44.9)$ & $22(44.9)$ & 1 & 0.00 \\
\hline TR grade $>2$ & $25(10.8)$ & $13(24.0)$ & .01 & 0.35 & $11(22.4)$ & $11(22.4)$ & 1 & 0.00 \\
\hline CAD & $18(7.8)$ & $3(5.6)$ & .55 & 0.09 & $2(4.1)$ & $3(6.1)$ & .64 & 0.03 \\
\hline LVDd & $57.9 \pm 6.2$ & $60.4 \pm 6.2$ & .015 & 0.40 & $59.1 \pm 6.5$ & $60.4 \pm 4.8$ & .015 & 0.23 \\
\hline LAD & $49.4 \pm 7.7$ & $50.9 \pm 8.7$ & .27 & 0.18 & $50.9 \pm 6.7$ & $50.7 \pm 7.6$ & .27 & 0.03 \\
\hline$\% \mathrm{FS}$ & $38.6 \pm 6.2$ & $37.1 \pm 6.1$ & .16 & 0.24 & $37.1 \pm 5.9$ & $37.6 \pm 5.7$ & .16 & 0.09 \\
\hline Thyroid disorder & $12(5.2)$ & $1(1.8)$ & .24 & 0.19 & $0(0)$ & $1(2.0)$ & .23 & 0.20 \\
\hline
\end{tabular}

Values are presented as mean \pm standard deviation or $\mathrm{n}(\%) . d$, Standardized difference; $B S A$, body surface area; $N Y H A$, New York Heart Association; $C C B$, calcium channel blocker; $H T$, hypertension; $H L$, hyperlipidemia; $D M$, diabetes mellitus; $F E V_{l}$, forced expiratory volume in one second; $C R F$ on $H D$, chronic renal failure on hemodialysis; $A f$, atrial fibrillation; $T R$, tricuspid regurgitation; $C A D$, coronary artery disease; $L V D d$, left ventricular end-diastolic diameter; $L A D$, left atrial diameter; $\% F S$, fractional shortening.

TABLE E5. Univariate and multivariate predictors for mitral insufficiency (MI) $\geq \mathbf{3}$ at follow-up and reoperation

\begin{tabular}{|c|c|c|c|c|}
\hline Variable & Univariate $P$ value & Multivariate hazard ratio & 95 $\%$ Confidence interval & $P$ value \\
\hline \multicolumn{5}{|c|}{ Risk factors for MI $\geq 3$ at follow-up } \\
\hline Postoperative MI grade $\geq 2$ & .0001 & 19.7 & $10.81-35.49$ & $<.0001$ \\
\hline Anterior group & .0003 & 2.7 & $1.22-5.98$ & .016 \\
\hline Partial band & .12 & 1.6 & $0.85-3.28$ & .14 \\
\hline Resection and suture & .84 & 1.3 & $0.74-2.6$ & .32 \\
\hline Chordal replacement & .001 & 1.9 & $0.89-3.83$ & .09 \\
\hline Edge to edge repair & .37 & 1.4 & $0.67-2.93$ & .37 \\
\hline \multicolumn{5}{|c|}{ Risk factors for MI $\geq 3$ at follow-up in anterior group } \\
\hline Partial band & .0134 & 2.8 & $1.3-6.7$ & .0069 \\
\hline Resection and suture & .26 & 1.9 & $0.9-4.5$ & .08 \\
\hline Chordal replacement & .46 & 1.3 & $0.5-3.7$ & .5 \\
\hline Edge-to-edge repair & .32 & 0.8 & $0.3-1.9$ & .69 \\
\hline \multicolumn{5}{|l|}{ Risk factors for reoperation } \\
\hline Female sex & .07 & & & \\
\hline Smaller BSA & .09 & & & \\
\hline Anterior group & .001 & 4.34 & $1.76-12.2$ & .0012 \\
\hline With CABG & .15 & & & \\
\hline
\end{tabular}

The anterior group was made up of those patients with anterior leaflet prolapse and the posterior group had posterior leaflet prolapse. $M I$, Mitral insufficiency; $B S A$, body surface area; $C A B G$, coronary artery bypass grafting. 
TABLE E6. Causes of reoperation

\begin{tabular}{lccc}
\hline \multicolumn{1}{c}{ Variable } & $\begin{array}{c}\text { Anterior } \\
(\mathbf{n}=\mathbf{1 5})\end{array}$ & $\begin{array}{c}\text { Posterior } \\
(\mathbf{n}=\mathbf{6})\end{array}$ & $\boldsymbol{P}$ value \\
\hline Reasons for reoperation & & & \\
$\quad$ Hemolysis & 9 & 2 & .26 \\
NYHA $\geq 3$ due to MI & 8 & 1 & .12 \\
Infective endocarditis & 0 & 2 & .1 \\
Findings & & & \\
Ring detachment & 5 & 1 & .42 \\
Prolapse & 6 & 2 & .77 \\
Tethering & 7 & 1 & .2 \\
\hline
\end{tabular}

The anterior group included patients with anterior leaflet prolapse and the posterior group included those with posterior leaflet prolapse. NYHA, New York Heart Association classification (graded I-IV); MI, mitral insufficiency.

TABLE E7. The number of missing values in each group for variables in Table 1

\begin{tabular}{lrcc}
\hline & All & Anterior (\%) & Posterior (\%) \\
\hline Patient No. & 452 & 167 & 285 \\
Age (y) & 0 & 0 & 0 \\
Men & 0 & 0 & 0 \\
BSA $\left(\mathrm{m}^{2}\right)$ & 0 & 0 & 0 \\
Af & 1 & 1 & 0 \\
Preoperative echocardiography findings & & \\
MI & 0 & 0 & 0 \\
LVDd (mm) & 0 & 0 & 0 \\
LVDs (mm) & 0 & 0 & 0 \\
LAD (mm) & 3 & 1 & 2 \\
TRPG (mm Hg) & 64 & 23 & 41 \\
\%FS & 13 & 1 & 12 \\
TR & 0 & 0 & 0 \\
Repair technique & & & \\
Partial band & 0 & 0 & 0 \\
Resection and suture & 0 & 0 & 0 \\
Chordal replacement & 0 & 0 & 0 \\
Edge to edge & 0 & 0 & 0 \\
Concomitant procedure & & & 0 \\
Maze & 0 & 0 & 0 \\
TAP & 0 & 0 & 0 \\
CABG & 0 & 0 & 0 \\
Other & 0 & 0 & 0 \\
\hline BSA Body sufac & & \\
\hline
\end{tabular}

$B S A$, Body surface area; $A f$, atrial fibrillation; $M I$, mitral insufficiency; $L V D d$, left ventricular end-diastolic diameter; $L V D s$, left ventricular end-systolic diameter; $L A D$, left atrial diameter; $T R P G$, tricuspid regurgitant pressure gradient; $\% F S$, fractional shortening; $T R$, tricuspid regurgitation; $T A P$, tricuspid annuloplasty; $C A B G$, coronary artery bypass grafting. 